\title{
GM-CSF Fails to Improve Immune Responses to Booster Hepatitis B Vaccination in HIV-Infected Individuals
}

\author{
Edgar T. Overton ${ }^{*}, 1$, Somnuek Sungkanuparph ${ }^{2}$, Michael Klebert ${ }^{1}$, Michael Royal ${ }^{1}$, \\ Debra Demarco-Shaw ${ }^{1}$, William G. Powderly ${ }^{3}$ and Judith A. Aberg ${ }^{4}$ \\ ${ }^{I}$ Washington University, St Louis, MO, USA \\ ${ }^{2}$ Faculty of Medicine Ramathibodi Hospital, Mahidol University, Bangkok, Thailand \\ ${ }^{3}$ School of Medicine and Medicine Sciences, University College Dublin, Dublin, Ireland \\ ${ }^{4}$ New York University, New York, NY, USA
}

\begin{abstract}
Background: Hepatitis B (HBV) vaccination is an important preventive intervention for HIV-infected population. Data regarding booster HBV vaccine for persons with low HBV surface antibody (sAb) titers after vaccination in this immunocompromised population is lacking.

Methods: We randomized $60 \mathrm{HIV}$-infected subjects lacking HBV protection after completion of 3 doses of HBV vaccine to receive a booster dose of HBV vaccine with $250 \mathrm{mcg}$ GM-CSF as an adjuvant or booster vaccine alone.

Results: GM-CSF was safe with expected side effects. However, only 35\% of persons receiving GM-CSF developed protective sAb while $50 \%$ in vaccine only arm developed protection $(\mathrm{P}=0.47)$. Overall, only $28 \%$ of subjects maintained protective $\mathrm{sAb} 1$ year after vaccination.

Conclusions: GM-CSF failed to improve responses to the booster HBV vaccination. Overall, response was poor with only $42 \%$ of persons responding at one month post-vaccination confirming booster vaccination with the current HBV vaccine has poor immunogenicity among HIV-infected persons. Further research is needed to develop optimal vaccination strategies in HIV-infected persons.
\end{abstract}

Keywords: HIV, HBV vaccination, GM-CSF, adjuvant.

\section{BACKGROUND}

Hepatitis B virus (HBV), the leading worldwide cause of chronic liver disease $[1,2]$, shares routes of transmission with Human Immunodeficiency virus (HIV) as manifest by the $30-90 \%$ of HIV-infected patients having evidence of prior HBV infection and $10 \%$ with chronic infection [3]. In the current era of effective antiretroviral therapy (ART), liver disease among HIV-infected populations is becoming more prominent as AIDS related morbidity and mortality declines [4-8]. Current guidelines recommend HBV vaccination for all HIV-infected persons who do not have evidence of current or past exposure to $\operatorname{HBV}[9,10]$.

While vaccination with recombinant $\mathrm{HBV}$ vaccine yields durable protection in greater than $90 \%$ of vaccinated immunocompetent adults [11,12], HIV-infected persons respond poorly to vaccination with response rates ranging from 17 to $56 \%$ with standard $\mathrm{HBV}$ vaccination strategies [13-16]. Therefore, current guidelines for the prevention of HBV infection recommend completing a three dose vaccine series with double dose vaccine $(40 \mathrm{mcg})$ with subsequent evaluation of HBsAb titers one month after vaccination and

*Address correspondence to this author at the Division of Infectious Diseases, Washington University School of Medicine, 660 S Euclid Ave, Campus Box 8011, St Louis, MO 63110, USA; Tel: (314) 454-8225; Fax: (314) 4545392; E-mail: toverton@dom.wustl.edu annually to assess durable immunity. In immunocompromised persons such as HIV-infected persons, protective immunity persists only while $\mathrm{HBsAb} \geq 10 \mathrm{mIU} / \mathrm{mL}[17,18]$. When the antibody level is below this protective level, booster vaccination is recommended [19].

Given the poor immunogenicity of HBV vaccine in HIVinfected persons, several studies have looked at various strategies, including booster vaccinations and the use of adujvants to boost the immune response. Recombinant granulocyte-macrophage colony-stimulating factor (GMCSF) is a cytokine produced primarily by activated $\mathrm{T}$ and $\mathrm{B}$ lymphocytes that has been used extensively as a hematopoietic growth factor. It increases neutrophil count, improves APC function, and is involved in the development and perpetuation of cellular immune responses [20]. GMCSF has been studied as an adjuvant to HBV vaccination in persons with end stage renal disease and HIV-infected individuals. A meta-analysis of 13 studies evaluating GM$\mathrm{CSF}$ as an adjuvant for $\mathrm{HBV}$ vaccine yielded a $50 \%$ increase in the development of seroprotection after a single dose of vaccine and a 20\% increase after the 3 dose series [21].

We hypothesized that GM-CSF would serve as an adjuvant to augment the response to a booster dose of HBV vaccine in HIV infected patients who failed the standard 3 dose HBV vaccine series. This approach has proven effective in end stage renal disease patients and dialysis patients, 
another group of immunocompromised patients [22-24]. This study was developed to evaluate the use of GM-CSF as an adjuvant will augment the response to booster vaccination in a cohort of HIV-infected persons previously vaccinated against $\mathrm{HBV}$.

\section{METHODS}

This study was performed at a single site with 60 participants enrolled. Study participants were HIV-infected volunteers without serologic evidence of prior hepatitis B infection (negative HBV sAg and negative HBV cAb) and who had failed to respond to $\mathrm{HBV}$ vaccination, as documented by a HBV surface $\mathrm{Ab}<10 \mathrm{mIU} / \mathrm{mL}$ after completing the 3 dose HBV vaccination series. Participants were required to be $\geq 18$ years of age and to have a current CD4 cell count $>100$ cells $/ \mathrm{mL}$ at time of entry. Exclusion criteria included current pregnancy, prisoners, other medical conditions which may be contraindication for receipt of GM$\mathrm{CSF}$, and anticipated inability to complete the requirements of the study.

The study was approved by the Washington University Human Research Protection Office and written informed consent was obtained from all study participants prior to study initiation. After consent was obtained, participants were stratified based on the level of plasma HIV RNA level into two groups: those with $>400$ copies $/ \mathrm{mL}$ and those with $\leq 400$ copies $/ \mathrm{mL}$.

All subjects received a single IM booster dose of $40 \mathrm{mcg}$ of recombinant HBV vaccine (Recombivax $\left.{ }^{\circledR}\right)$ in the deltoid muscle. The subjects randomized to the GM-CSF arm then received an IM dose of $250 \mathrm{mcg}$ of GM-CSF (Leukine ${ }^{B}$ ) into the same deltoid muscle. Baseline demographic data as well as clinical parameters related to vaccine non-response (age, race, gender, BMI, smoking, HCV status) and HIV parameters were collected at baseline.

\section{STUDY ENDPOINTS}

The primary endpoints in this study were the quantitative $\mathrm{HBV} \mathrm{sAb}$ and the seroconversion rates, defined as HBV sAb titer $\geq 10 \mathrm{mIU} / \mathrm{mL} 1$ month after vaccination. Secondary endpoints included safety and tolerability of the vaccine and GM-CSF, changes in CD4 cell count, and plasma HIV viral load at 1 month, and quantitative HBsAb at 12 months.

Subjects were monitored for 30 minutes after vaccination for adverse reactions and then received a phone call at 48 hours for evaluation of any adverse symptoms. Participants returned at day 7 and day 28 for a targeted physical examination including vital signs, evaluation of the injection site and focusing on any specific signs or symptoms. Laboratory evaluation was performed at day 7 and 28 to monitor changes in blood counts. Participants returned at week 48 for final quantitative HBsAb.

\section{STATISTICAL ANALYSIS}

Based on an expected development of HBV $\mathrm{sAb} \geq$ $10 \mathrm{mIU} / \mathrm{ml}$ of $60 \%$ in the GM-CSF arm and $20 \%$ in the vaccine only arm, we estimated a sample size of 48 . This calculation is based on a two-sided $\alpha=0.05$ and a $\beta=0.10$. Based on an assumed $20 \%$ drop-out rate, we enrolled a total of 60 participants to the study, 30 participants in each arm.
Differences between groups were determined using Student's t-test for normally distributed continuous variables, Mann-Whitney U test for continuous variables not normally distributed, and Chi squared test for proportions. All analyses were two-tailed and significance was considered if the $\mathrm{p}$-value $\leq 0.05$.

\section{RESULTS}

Sixty HIV-infected subjects, aged 20-60 years (mean age 37.9 years) were enrolled in the study in 2005 and 2006. The majority of the study participants were African American $(72 \%)$ and female (58\%). Forty two subjects were on ART at study entry with $32(76 \%)$ of those having HV RNA $<400$ $\mathrm{cp} / \mathrm{mL}$. Other baseline parameters are listed in Table 1. All subjects received vaccine or vaccine and GM-CSF and were available for initial safety and tolerability assessment. Four subjects were found to have reactive HBV $\mathrm{cAb}$ at day 7 assessment and were excluded from subsequent antibody evaluation, leaving 27 subjects in the vaccine only arm and 29 subjects in the vaccine plus GM-CSF arm. Twenty six participants in each arm completed the 48 week efficacy assessment; in the intervening period, three relocated out of the area and one was lost to follow-up.

\section{IMMUNE RESPONSES}

Responses to booster vaccination were poor for both groups. Overall, only $42 \%$ of subjects developed a protective antibody response (HBsAb $\geq 10 \mathrm{mIU} / \mathrm{mL}$ ). Although there was a trend for more responders in the vaccine only arm $(50 \%$ vs $35 \%)$, the numbers are small and the results are not significant. There was a decrease in antibody responses from 1 month to 1 year in both arms of the study ( $28 \%$ overall). Table 2 shows the immune responses for the two study groups. The development of protective $\mathrm{Ab}$ response was not associated with any of the baseline factors including CD4 cell count or level of HIV viremia at time of vaccination.

\section{SAFETY AND SIDE EFFECTS}

All subjects received a follow-up phone interview at 48 hours to assess for side effects. Twenty one subjects reported at least one side effect, four in the vaccine only arm and seventeen in the GM-CSF arm $(p<0.001)$. All side effects were mild (grade 1 by the DAIDS toxicity table) and resolved within the first 24 hours after vaccination. No participant had a side effect requiring bed rest, loss of work, or cancellation of social activities. Adverse events are shown in Table 3.

\section{DISCUSSION}

These data illustrate that GM-CSF is safe with expected side effects in HIV-infected subjects when administered as an adjuvant for booster HBV vaccination. Unfortunately, in this study there was no benefit to giving this adjuvant to improve responses in HIV-infected subjects who have failed to respond to the initial series of HBV vaccination. Furthermore, the use of booster vaccination failed to yield protection in a majority of HIV-infected subjects.

In immunocompetent persons, protection from $\mathrm{HBV}$ infection remains intact even when $\mathrm{HBsAb}$ titers wane $<10 \mathrm{mIU} / \mathrm{mL}$. Immune memory is preserved and when confronted with HBV sAg (either by exposure to virus or 
Table 1. Baseline Demographics and Other Factors

\begin{tabular}{|c|c|c|c|}
\hline & Vaccine Only $(n=30)$ & Vaccine + GM-CSF $(n=30)$ & p-Value \\
\hline Mean Age \pm SD (in years) & $38.5 \pm 10.0$ & $37.3 \pm 9.7$ & 0.619 \\
\hline $\begin{array}{l}\text { Race } \\
\qquad \text { AA } \\
\text { Caucasian }\end{array}$ & $\begin{array}{c}23(76.7 \%) \\
7(23.3 \%)\end{array}$ & $\begin{array}{l}20(66.7 \%) \\
10(33.3 \%)\end{array}$ & 0.390 \\
\hline $\begin{array}{l}\text { Gender } \\
\text { Female } \\
\text { Male }\end{array}$ & $\begin{array}{l}17(56.7 \%) \\
13(43.3 \%)\end{array}$ & $\begin{array}{l}18(60 \%) \\
12(40 \%)\end{array}$ & 0.793 \\
\hline Mean BMI \pm SD & $29.3 \pm 7.6$ & $30.3 \pm 11.1$ & 0.691 \\
\hline Current smoker & $11(36.7 \%)$ & $10(33.3 \%)$ & 0.787 \\
\hline Reactive $\mathrm{HCV} \mathrm{Ab}$ & $2(6.7 \%)$ & $1(3.3 \%)$ & 0.554 \\
\hline Mean $\log _{10}$ plasma HIV RNA \pm SD & $2.7 \pm 1.1$ & $3.0 \pm 1.2$ & 0.455 \\
\hline $\begin{array}{l}\text { Plasma HIV RNA } \\
<400 \text { copies } / \mathrm{mL}\end{array}$ & $16(53.3 \%)$ & $16(53.3 \%)$ & 1.0 \\
\hline Median Nadir CD4 count (IQR) & $162(71-271)$ & $207(91-304)$ & 0.429 \\
\hline Median CD4 count at enrollment (IQR) & $375.5(290-663)$ & $425(288-564)$ & 0.865 \\
\hline On ART at enrollment & $21(70 \%)$ & $21(70 \%)$ & 1.0 \\
\hline
\end{tabular}

Table 2. Immune Responses

\begin{tabular}{|c|c|c|c|}
\hline & Vaccine Only & Vaccine + GM-CSF & p-Value \\
\hline $\begin{array}{l}\text { Median } 1 \text { month HBsAb } \\
\text { (range) }\end{array}$ & $\begin{array}{l}9.4 \mathrm{mIU} / \mathrm{mL} \\
(0->2000)\end{array}$ & $\begin{array}{l}0 \mathrm{mIU} / \mathrm{mL} \\
(0->2000)\end{array}$ & NS \\
\hline $\begin{array}{l}\% \text { with } \mathrm{HBsAb}>10 \mathrm{mIU} / \mathrm{mL} \\
\text { at } 1 \text { month }\end{array}$ & $\begin{array}{c}50 \% \\
(14 / 28)\end{array}$ & $\begin{array}{c}35 \% \\
(10 / 29)\end{array}$ & 0.47 \\
\hline $\begin{array}{l}\text { Median } 1 \text { year HBsAb } \\
\quad \text { (range) }\end{array}$ & $\begin{array}{c}0 \mathrm{mIU} / \mathrm{mL} \\
(0-1000)\end{array}$ & $\begin{array}{c}0 \mathrm{mIU} / \mathrm{mL} \\
(0-258)\end{array}$ & NS \\
\hline $\begin{array}{l}\% \text { with } \mathrm{HBsAb}>10 \mathrm{mIU} / \mathrm{mL} \\
\text { at } 1 \text { year }\end{array}$ & $\begin{array}{c}33 \% \\
(9 / 27)\end{array}$ & $\begin{array}{l}23 \% \\
(6 / 26)\end{array}$ & 0.71 \\
\hline
\end{tabular}

Table 3. Adverse Events

\begin{tabular}{|c|c|c|c|}
\hline & Vaccine Only & Vaccine + GM-CSF & p-Value \\
\hline Any adverse event* & $4(13.3 \%)$ & $17(56.7 \%)$ & $<0.001$ \\
\hline Soreness at injection site & $0(0 \%)$ & $2(7.7 \%)$ & 0.150 \\
\hline Redness at injection site & $0(0 \%)$ & $0(0 \%)$ & 1.0 \\
\hline Headache & $3(10 \%)$ & $10(33.3 \%)$ & 0.028 \\
\hline Fever & $3(10 \%)$ & $8(26.7 \%)$ & 0.095 \\
\hline Chest pain & $0(0 \%)$ & $2(7.7 \%)$ & 0.150 \\
\hline Dyspnea & $1(3.3 \%)$ & $1(3.3 \%)$ & 1.0 \\
\hline
\end{tabular}

* Other reported side effects included itching, back pain, leg pain, nausea, dizziness, nasal congestion, and swollen tongue

All adverse events were grade 1 and resolved within 24 hours.

vaccine), a clonal expansion of memory $\mathrm{B}$ and $\mathrm{T}$ lymphocytes occurs, yielding measurable titers of HbsAb and preventing infection [25]. A recent review by Leuridan and Van Damme compiled data from 13 published studies highlighting a robust anamnestic response to a booster HBV vaccine $(62-100 \%)$ in HIV negative populations [26]. Furthermore, Bauer et al. illustrated persistent T and B-cell memory in $\mathrm{HBV}$ vaccinees with $\mathrm{HBs} A \mathrm{~b}$ titers $<10 \mathrm{mIU} / \mathrm{mL}$ 
suggesting that measurable antibodies are not necessary for long term protection [27]. Finally, long term seroprevalence studies in high endemic countries report a marked decrease in incidence of acute HBV and prevalence of chronic HBV carriage since the inception of universal vaccination. Taiwan serves as an excellent example where the HBV carrier rate has declined from $9.8 \%$ before universal vaccination to $0.8 \%$ 23 years after the commencement of the program [28,29]. The data from these different types of studies (anamnestic responses, residual cellular immunity, and long-term epidemiologic studies) have led to the recommendation that booster vaccination is not necessary among healthy individuals $[26,30]$.

Immunocompromised patients, on the other hand, are at risk for $\mathrm{HBV}$ infection when $\mathrm{HBs} A b$ titer $<10 \mathrm{mIU} / \mathrm{mL}$. Data from dialysis patients and HIV-infected persons illustrate that $\mathrm{HBsAb}$ titers are significantly lower among immunocompromised patients compared to healthy controls and that the secondary immune response is not as robust [1319, 31]. Additionally, cases of confirmed HBV infection (HBsAg reactivity) have been reported among HIV-infected persons despite HBV vaccination [32-34]. Therefore, booster vaccine is recommended for persons with immunocompromised states. Unfortunately, booster vaccine generally fails to yield protection in a large proportion of subjects. Our findings of $42 \%$ response in HIV-infected adults are similar to those recently reported in an ACTG pediatric study in which $46 \%$ of HIV-infected children developed protective immunity after a booster dose of HBV vaccine [35]. How do we enhance immune responses on these at risk populations?

Improving the response in immunocompromised patients remains challenging. While the initiation of HAART with subsequent increase in CD4 cell count and reduction in HIV viral load has been associated with improved vaccine responses in children and adolescents, the rates of response remain below that reported in healthy individuals [35]. The utility of alternative strategies, specifically alternative adjuvants are one mechanism to augment the response. In this study, we elected to evaluate GM-CSF as an adjuvant given previous data suggesting its utility for vaccine responses in both dialysis patients and HIV-infected persons [21-23,36]. Unfortunately, the current study failed to find similar benefit with GM-CSF. Rather, the findings are similar to results recently published which evaluate the use of GM-CSF as an adjuvant for primary HBV vaccine series in HIV-infected persons [37]. One question is whether the difference in dosing strategies used in these studies accounts for the differences in responses reported or if there are factors related to the different populations, such as nadir or current CD4 cell counts, which may impact response.

Nevertheless, these data leave clinicians unclear of the appropriate management of vaccine non-responders and individuals with waning antibody titers. In HIV-infected individuals, the underlying cause for the poor and transient response remains intriguing. The altered immune system prevents the propagation of an appropriate memory response even among those on suppressive ART therapy. Additional research is needed to inform the best approach.

Our study is limited by a relatively small sample size. It is also limited by the fact that we cannot differentiate participants who were non-responders to the initial vaccine series versus those who responded but had waning $\mathrm{HBsAb}$ titer. This latter fact may be important as those who initially respond may be good candidates for booster vaccination rather than require a repeat of the three dose vaccination series. The time from receipt of the initial vaccine series and the booster dose was highly variable which also may impact the response to a booster vaccination.

The results from our study confirm that a single booster vaccine is unlikely to yield significant immune protection against HBV for the HIV-infected population. The alternative strategy of repeating the three dose vaccine series is an alternative strategy that may yield better results. The addition of GM-CSF as an adjuvant, an approach that has shown promise in other studies and in other immunocompromised populations, failed to improve responses in the present study. Continued efforts must strive to identify a more effective strategy for $\mathrm{HBV}$ vaccination in HIV-infected persons.

\section{AUTHOR DISCLOSURE STATEMENT}

No competing financial interests exist.

\section{REFERENCES}

[1] Lee W. Hepatitis B virus infection. N Engl J Med. 1997; 337 : 1733-45.

[2] Mahoney FJ. Update on diagnosis, management, and prevention of hepatitis B virus infection. Clin Microbiol Rev 1999; 12: 351-66.

[3] Homann C, Krogsgaard K, Pedersen C, et al. High incidence of hepatitis B infection and evolution of chronic hepatitis B infection in patients with advanced HIV infection. J AIDS 1991; 4: 416-20.

[4] Gilson RJ, Hawkins AE, Beecham MR et al. Interactions between HIV and hepatitis B in homosexual men: effects on the natural history of infection. AIDS 1997; 11: 597-606.

[5] Thio CL, Seaberg EC, Skolasky R Jr, et al. HIV-1, hepatitis B, and risk of liver-related mortality in the Multicenter AIDS Cohort Study (MACS). Lancet 2002; 360: 1921-6.

[6] Eskild A, Magnus P, Petersen G et al. Hepatitis B antibodies in HIV-infected homosexual men are associated with more rapid progression to AIDS. AIDS 1992; 6: 571-4.

[7] Solomon RE, Van Raden M, Kaslow RA, et al. Association of hepatitis B surface antigen and core antibody with acquisition and manifestations of HIV-1 infection. Am J Public Health 1990; 80: 1475-8.

[8] Konopnicki D, Mocroft A, de Wit S, et al. Hepatitis B and HIV: prevalence, AIDS progression, response to highly active antiretroviral therapy and increased mortality in the EuroSIDA cohort. AIDS 2005; 19: 593-601.

[9] Mast EE, Weinbaum CM, Fiore AE, et al. A comprehensive immunization strategy to eliminate transmission of hepatitis B virus infection in the United States: recommendations of the Advisory Committee on Immunization Practices (ACIP) Part II: immunization of adults. MMWR Recomm Rep 2006; 55: 1-33.

[10] Kaplan JE, Benson C, Holmes KH, et al. Guidelines for prevention and treatment of opportunistic infections in HIV-infected adults and adolescents: recommendations from CDC, the National Institutes of Health, and the HIV Medicine Association of the Infectious Diseases Society of America. MMWR Recomm Rep 2009; 58: 1-207.

[11] Bloom BS, Hillman AL, Fendrick AM, et al. A reappraisal of hepatitis $B$ vaccination strategies using cost effectiveness analysis. Ann Intern Med 1993; 118: 298-306.

[12] Van Herck K, Van Damme P, Thoelen S, Meheus A. Long-term persistence of antiHBs after vaccination with a recombinant DBA yeast-derived hepatitis B vaccine: 8 year results. Vaccine 1998; 16: 1933-5.

[13] Keet IP, van Doornum G, Safary A, Coutinho RA. Insufficient response to hepatitis $\mathrm{B}$ vaccination in HIV-positive homosexual men. AIDS 1992; 6: 509-10. 
[14] Tayal SC, Sankar KN. Impaired response to recombinant hepatitis B vaccine in asymptomatic HIV infected individuals. AIDS 1994; 8: 558-9.

[15] Bruguera M, Cremades M, Salinas R, Costa J, Grau M, Sans J. Impaired response to recombinant hepatitis $\mathrm{B}$ vaccine in asymptomatic HIV infected persons. J Clin Gastroenterol 1992; 14: 27-30.

[16] Overton ET, Sungkanuparph S, Powderly WG, et al. Undetectable plasma HIV RNA load predicts success after hepatitis B vaccination in HIV-infected persons. Clin Infect Dis 2005; 41: $1045-8$.

[17] Hadler SC, Coleman PJ, O'Malley P, Judson FN, Altman N. Evaluation of long-term protection by hepatitis B vaccine for seven to nine years in homosexual men. In: Hollinger FB, Lemon SM, Margolis H, Eds. Viral hepatitis and liver disease: proceedings of the 1990 International Symposium on Viral Hepatitis and Liver Disease. Baltimore, MD: Williams \& Wilkins; 1991; pp. 776-8.

[18] Stevens CE, Alter HJ, Taylor PE, Zang EA, Harley EJ, Szmuness W. Hepatitis B vaccine in patients receiving hemodialysis. Immunogenicity and efficacy. N Engl J Med 1984; 311: 496--501.

[19] Centers for Disease Control and Prevention. Update: recommendations to prevent hepatitis B virus transmission--United States. MMWR Recomm Rep 1999; 48: 33-4.

[20] Deresinki SC. Granulocyte-macrophage colony-stimulating factor: potential therapeutic, immunologic and antiretroviral effects in HIV infection. AIDS 1999; 13: 633-43.

[21] Cruciani M, Mengoli C, Serpelloni G, Mazzi R, Bosco O, Malena M. Granulocyte macrophage colony-stimulating factor as an adjuvant for hepatitis B vaccination: a meta-analysis. Vaccine 2007; 25: 709-18.

[22] Jha R, Lakhtakia S, Jaleel MA, et al. Granulocyte-macrophage colony-stimulating factor induced sero-protection in end stage renal failure patients to hepatitis B in vaccine non-responders. Ren Fail 2001; 23: 629-36.

[23] Hess G, Kreiter F, Kosters W, et al. The effect of granulocytemacrophage colony-stimulating factor (GM-CSF) on hepatitis B vaccination in haemodialysis patients. J Viral Hepatitis 1996; 3: 149-53.

[24] Evans TG, Schiff M, Graves B, et al. The safety and efficacy of GM-CSF as an adjuvant in hepatitis B vaccination of chronic hemodialysis patients who have failed primary vaccination. Clin Nephrol 2000; 54: 138-42.

[25] Banatvala JE, Van Damme P. Hepatitis B vaccine---do we need boosters? J Viral Hepatitis 2003; 10: 1-6.
[26] Leuridan E, Van Damme P. Hepatitis B and the need for a booster dose. Clin Infect Dis 2011; 53: 68-75.

[27] Bauer T, Jilg W. Hepatitis B surface antigen-specific T and B cell memory in individuals who had lost protective antibodies after hepatitis B vaccination. Vaccine 2006; 24: 572-7.

[28] Chen CY, Hsu HY, Liu CC, Chang MH, Ni YH. Stable seroepidemiology of hepatitis B after universal immunization in Taiwan: A 3-year study of national surveillance of primary school students. Vaccine 2010; 28: 5605-8.

[29] Chang HC, Yen CJ, Lee YC, Chiu TY, Jan CF. Seroprevalence of hepatitis B viral markers among freshmen--20 years after mass hepatitis B vaccination program in Taiwan. J Formos Med Assoc 2007; 106: 513-9.

[30] European Consensus Group on Hepatitis Immunity. Are booster immunisations needed for lifelong hepatitis B immunity? Lancet 2000; 355: 561-5.

[31] Tsouchnikas I, Dounousi E, Xanthopoulou K, Papakonstantinou S, Thomoglou V, Tsakiris D. Loss of hepatitis B immunity in hemodialysis patients acquired either naturally or after vaccination. Clin Nephrol 2007; 68: 228-34.

[32] Emerson CR, Post JJ, Kelly MD. Acute hepatitis B virus infection despite previous immunization in the context of recent HIV-1 infection. AIDS 2010; 24: 2137-8.

[33] Van der Linden D, Cotton M, Rabie H, McKerrow N. Fatal hepatitis B infection despite immunization in an HIV-infected infant: a possible case of vaccine failure and immune reconstitution inflammatory syndrome. J Trop Pediatr 2010; 56: 351-4.

[34] Landrum ML, Hullsiek KH, Ganesan A, et al. Hepatitis B vaccination and risk of hepatitis B infection in HIV-infected individuals. AIDS 2010; 24: 545-55.

[35] Abzug MJ, Warshaw M, Rosenblatt HM, et al. International Maternal Pediatric Adolescent AIDS Clinical Trials Group P1024 and P1061s Protocol Teams. Immunogenicity and immunologic memory after hepatitis B virus booster vaccination in HIV-infected children receiving highly active antiretroviral therapy. J Infect Dis 2009; 200: 935-46.

[36] Sasaki MG, Foccacia R, de Messias-Reason IJ. Efficacy of granulocyte-macrophage colony-stimulating factor (GM-CSF) as a vaccine adjuvant for hepatitis $B$ virus in patients with HIV infection. Vaccine 2003; 21: 4545-9.

[37] Overton ET, Kang M, Peters MG, et al. Immune Response to Hepatitis B Vaccine in HIV-Infected Subjects Using GranulocyteMacrophage Colony-Stimulating Factor (GM-CSF) as a Vaccine Adjuvant: ACTG Study 5220. Vaccine 2010; 28: 5597-604.

This is an open access article licensed under the terms of the Creative Commons Attribution Non-Commercial License (http: //creativecommons.org/licenses/by-nc/ 3.0/) which permits unrestricted, non-commercial use, distribution and reproduction in any medium, provided the work is properly cited. 